\title{
Can Life Satisfaction Independently Predict Suicidal Ideation of Male And Female?
}

\author{
Muhammad Alamgir Hossain ${ }^{1}$, Lisa Paul ${ }^{2}$, Md. Towhidul Islam ${ }^{3}$
}

\section{ABSTRACT}

The aim of the research was to determine the effect of life satisfaction on suicidal ideation for both male and female undergraduate students. Data were collected from 120 students (60 male and 60 female) who were purposively chosen from University of Chittagong of Bangladesh. To measure the constructs, Bangla version of life satisfaction and suicidal ideation scales were used in the present study. Results revealed that there were no significant gender differences in life satisfaction and suicidal ideation. But the participants who had bitter experiences in romantic relationship significantly scored higher on suicidal ideation than who had not $(\mathrm{t}=2.76, \mathrm{p}<.01)$. There was found a significant negative correlation coefficient between life satisfaction and suicidal ideation $(r=-.316, \mathrm{p}<.01)$. A simple regression analysis confirmed that life satisfaction was a strong predictor $(\beta=-.466, p<.001)$ and explained $21 \%$ variation of suicidal ideation for female students. Whereas life satisfaction did not significantly predict suicidal ideation of male students $(\beta=-1.66, \mathrm{p}>$.05).

Keywords: Life Satisfaction, Suicidal Ideation, Male, Female, Prediction.

Suicide as described by Kachur, Potter, Powell, and Rosenberg, (1995) is the end of a sequence that commences with suicidal ideation, follows by planning and preparing for suicide and ends with threatening, attempting and completing suicide. It is not easy to say why some people do suicide while others do not in a similar or even worse situation (Rihmer, 2007). Suicide involves different causal factors such as biological, psychological, psychosocial, and socio-cultural factors.

\section{Suicidal Ideation:}

Suicide ideation, thoughts of hurt or killing oneself, is a familiar medical term for thoughts about suicide without the suicidal act itself. While most people who have suicidal ideation do not

\footnotetext{
${ }^{1}$ Lecturer, Department of Psychology, University of Chittagong, Chittagong-4331, Bangladesh

${ }^{2}$ Lecturer, Department of Psychology, University of Chittagong, Chittagong-4331, Bangladesh

${ }^{3}$ Graduate Student, Department of Psychology, University of Chittagong, Chittagong-4331, Bangladesh

*Responding Author

(c) 2016 I M Hossain, L Paul, T Islam; licensee IJIP. This is an Open Access Research distributed under the terms of the Creative Commons Attribution License (http://creativecommons.org/licenses/by/2.0), which permits unrestricted use, distribution, and reproduction in any Medium, provided the original work is properly cited.
} 


\section{Can Life Satisfaction Independently Predict Suicidal Ideation of Male And Female?}

commit suicide, some take suicide attempts (Beck, Steer, Kovacs, \& Garison, 1985). Suicide ideation, explained as thoughts of engaging behavior aimed at end one's life, needs greater research attention because it is an important precursor to suicide attempts (Reinherz, et al., 1995; Lewinsohn, Rohde, \& Seeley, 1994).

Moreover, suicide ideation is an antecedent cause not only for attempting but also completing suicide (Goldstaein, Black, Nasralla, \& Winokur, 1991; Alexopoulos et al., 1999) and a common symptom to clinicians of the need for further risk appraisal (Olfson, Weissman, Leon, Sheehan, \& Farbre, 1996). Suicidal ideation can be passive (when there are only thoughts of suicide but no intention to commit suicide) or active (when there are plans or thoughts of causing one's own death).

\section{Life Satisfaction:}

Life satisfaction is a cognitive aspect or subjective evaluation of happiness which refers to general evaluation of individual's life (Diener, Suh, \& Oishi, 1997; Frisch, 1998)). The notion of life satisfaction is an important issue to be studied because it is not only foundation of welfare and health but also associated with increasing longevity, quality, meaningful and welfare of life (Ozer, 2000).

Global life satisfaction is hoped to affect the possibility of consequent emotional and behavioral responses in relation to specific life events (Deiner, 1994; Lazarus, 1991). So, even if determining a degree of short-term and long-term stability, (Gilman, \& Huebner, 1997; Huebner, Funk, \& Gilman, 2000), changes in overall life satisfaction may evoke change in adolescent coping strategies. For instance, some people might respond to decrease in life satisfaction and related emotions by engaging in different risk taking behaviors associated to health (such as, suicidal ideation and suicide attempts).

\section{LITERATURE REVIEW}

As reported by the World Health Organization's (WHO) 2016, Over 800,000 people commit suicide per year in the world- that's one person every 40 seconds die by suicide somewhere in the world. Prevalence of suicide in Bangladesh is high, though data from this area are unavailable in the statistics. According to the recent WHO data published in may 2014 suicide deaths came to 10,167 or $1.40 \%$ of total deaths in Bangladesh. But much attention has not been given still in this issue. There is also lack of research on suicide in Bangladesh. In agreement with The United News of Bangladesh (2012) more than 10,000 people commit suicide every year for various reasons. In Bangladesh suicide is one of the major causes of mortality, especially for women. After all, findings regarding on gender difference on various aspect of suicidal behavior are mixed. Most of the researches indicate that suicidal ideation is more prevalent among women than men across all countries and cultures (Chen, Lee, Wong, \& Kaur, 2005; Ruangkanchanasetr, Plitponkarnpim, Hetrakul, \& Kongsakon, 2005). But complete suicide rate is higher for boys than girls. Stephenson, Pena-Shaff, and Quirk, (2006) found that women 


\section{Can Life Satisfaction Independently Predict Suicidal Ideation of Male And Female?}

had higher levels of suicidal ideation than men. The same results were also found in the Indian studies conducted by Lagaraj, Felix, and Vedapriya, (2005). It has also reported by some other research studies that female students have higher rate of suicidal ideation than males (Sidhartha, \& Jena, 2006).

A study on a sample of 3700 Italian adolescents was conducted by Laghi, Baiocco, D'Alessio, and Gurrieri, (2009) to see the impact of time perspective on suicide ideation. It was recorded that $9.2 \%$ of the sample reported severe suicidal ideation during the last two weeks; $7.6 \%$ reported moderate suicidal ideation. Female adolescents were found to be reported more severe suicidal ideation as compared to males. According to Rich, Kirkpatrick-Smith, Bonner, \& Jans, (1992) and Adcock, Nagy, \& Simpson, (1991) female had higher suicidal ideation than male, but gender was not found to be a significant predictor of suicidal ideation. Zhang, \& Jin, (1996) identified that suicide thoughts and suicidal attempt rates were higher for females (34.7\%, $10.9 \%)$ than those for males $(22.2 \%, 4.9 \%)$.

However, an evidence for gender differences in suicidal ideation is blended. For instance, several studies have reported higher prevalence of suicidal ideation for males while others reported similar prevalence of suicidal ideation for males and females. Mackenzie, et al. (2011) found that the frequency of depression was almost similar for men (25\%) and women (26\%) among 1,622 college students. But suicidal ideation was higher for men (13\%) than women (10\%). Suicidal ideation of students was assessed by Stewart et al. (2008) from a large population. They measured over $10 \%$ of students reported that they had suicidal thoughts within previous few weeks, and boys scored slightly higher than girls on suicidal ideation. Many researchers did not found gender differences in suicidal thoughts (Sherer, 1985; Harlow, Michael, Newcomb, \& Bentler, 1985; Garrison, Jackson, Addy, McKeowan, \& Waller, 1991; Schweitzer, Klayich, \& McLean, 1995). Although similar suicidal thoughts were observed by McAuliffe, Carcoran, Keeley, \& Perry, (2003).

A study was conducted to investigate the associated risk factors of suicidal ideation among high school students and college students in China. The sample consisted of 5249 students who participated in a self- administered anonymous survey. The result indicated that lower life satisfaction and higher self-esteem were significantly associated with suicidal ideation. Moreover, female students reported more suicidal ideation than male students (Yao, et al., 2014).

A little research has devoted to investigate the factors responsible for developing suicidal ideation among students. Koivumaa-Honkanen, et al., (2001), using a 20-year follow up technique from a nationwide sample of adults aged 18-24 in Finland, found that life satisfaction had a long-term effect on the risk of suicidal ideation.

Lester, (1998) indicated the relation between life satisfaction and suicidal ideation in college students from 18 nations. Only one correlation was significant (e.g., female suicidal ideation and 


\section{Can Life Satisfaction Independently Predict Suicidal Ideation of Male And Female?}

satisfaction with (family) from ten different domains of correlations between life satisfaction and suicidal ideation (i.e., satisfaction with friends, family, self, life).

Satisfaction with life, the "cognitive judgmental" component of subjective well-being (Diener, Emmons, Larsen, \& Griffin, 1985), has been consistently positively associated with psychological adjustment (e.g., Diener, Sapyta, \& Suh, 1998) and negatively associated with depression (Pavot, \& Diener, 1993), suicidal ideation and intent (Haight, \& Hendrix, 1998), and self-reported suicide attempts (Heisel, \& Fus'e, 1999).

Lewinsohn, Hops, Roberts, Seeley, \& Andrews, (1993) reported that females were acquiring more risk factors and showing a higher susceptibility to risk factors than males did. According to Heisel, \& Flett, (in press) significant positive correlations were found between suicidal thoughts and negative psychological factors (e.g., depression, and global and social hopelessness) and significant negative correlations were noticed between suicidal thoughts and positive psychological factors (e.g., psychologial well-being, satisfaction with life, meaning and purpose in life) in 107 seniors. Moreover, Heisel, and Flett, (2004) also found life satisfaction was a predictor of suicidal ideation.

Students who have low life satisfaction experience suicide ideation. High life satisfaction advocates success later in life because it helps students' to start with good attitudes and opportunities in life. Many researchers found gender differences in life satisfaction. According to Hutchitson, et al. (2004) female reported less life satisfaction than male. Life satisfaction might affect students' entire life and support them to deal adequately with their emotion. Heisel, and Flett, (2004) found male students tend to be more satisfied with life than do female students.

However, Neg, Loy, Gudmunson, \& Cheong, (2009) examined that there was no significant difference on life satisfaction between male and female. Sandin, Chorot, Santed, Valiente, \& Joiner, (1998) investigated the association between negative life events and suicidal behavior. They found that life events can include a risk factor for students' suicidal behavior though its contribution tended to be moderate or feeble.

Gender differences in suicide thoughts are found significantly by Jamshiedzadeh, Rafiei, Yasami, Rahimi, \& Azam, (2001); Park, Koo, \& Schepp, (2005); and Lee, Tsang, Li, Phillips, \& Kleinman, (2007). As female students are more often than males reported suicidal ideation and suicide attempts as well as other problems (Tomory, Zalar, \& Plesnicar, 2000).

In order to reliably examine the importance and meaning of the relationship between satisfaction with life and suicidal ideation or suicide behavior among students much work needs to be done. Negative life events such as bitter experiences in romantic relationships, violent behaviors, and sexual risk taking behaviors have been found to be associated with suicidal ideation. This is why we conducted the current study with the aim of determining the effect of life satisfaction on risk for suicidal behavior in university students. 


\section{Can Life Satisfaction Independently Predict Suicidal Ideation of Male And Female?}

\section{Hypotheses}

1. Female students will score significantly higher on suicidal ideation than do male students.

2. Female students will score significantly lower on life satisfaction as compared to male students.

3. Students who had bitter experiences in romantic relationship will score significantly higher on suicidal ideation than students who did not have.

4. Significant negative correlation will be found between suicidal ideation and life satisfaction.

5. Life satisfaction will independently predict suicidal ideation of male and female students.

\section{METHOD}

\section{Participants}

In order to collect data, participants were selected purposively; a total 120 respondents were selected. Their age were ranged from 18-25 years. However, all the respondents of this study were students and they are now studying in a university. Among them 60 students were male (30 were residents and 30 were non residents) and 60 students were female (30 were residents and 30 were non residents). Their educational levels were Honors to Postgraduate ( ${ }^{\text {st }}$ year to MS). Respondents were from lower class to higher class family background.

\section{Measures}

In the present research the following two questionnaire were used such as

Suicidal Ideation Questionnaire. Suicidal ideation was measured using the Bangla version (Uddin \& Hossain, 2007) of Beck, Kovacs, Weissman, (1979). Suicidal ideation was assessed with 21-item self-report scale for suicidal ideation. The answer options for each item of the scale were 3 point scale. Such as “'0”, “ 1 ”’ and “' 2 ”'. So, higher scores reveal greater levels of suicide ideation. Each items assess suicidal criteria such as willing to die, wish to make an active or passive suicidal attempt, duration and frequency of thoughts, sense of control over accomplish an attempt, and number of obstacles. The instrument total score is the sum of the sum of the individual item scores and may range from 0 (low ideation) to 42 high (high ideation). Scale reliability is confirmed by moderately high internal consistency and good concurrent and discriminate validity (Beck, Brown, Steer, Dahlsgaard, \& Grisham, 1999). In the present sample, internal consistency was obtained, $\alpha=.94$.

Satisfaction with Life Scale (SWLS). Bangla version (Ilyas, 2001) of Diener, Emmons, Larsen, \& Griffin, (1985)'s Satisfaction with Life Scale (SWLS) was used to measure subjective life satisfaction. This 5-items scale measured person's global satisfaction with life. The English and Bangla versions were administered to 30 subjects with a gap of seven days. Significant correlation between English and Bangla version $[r(28)=.626, p<.001]$ indicated translation reliability of the scale. Highly significant correlation $[r(48)=.662, p<.001]$ between scores of two administrations indicated test-retest reliability of the Bangla version. High alpha coefficient ( $\alpha=$.7401) further indicated internal consistency of the scale. 


\section{Can Life Satisfaction Independently Predict Suicidal Ideation of Male And Female?}

\section{Design}

A cross-sectional survey research design was followed for conducting present study.

\section{Procedure}

Data were collected individually from each respondent. Respondents were told that the sole purpose of the investigation was academic and their response would be kept confidential. Before administration of the questionnaire, necessary rapport was established with respondents. Then, the suicidal ideation scale and life satisfaction scale were administered to respondents and requested a silent reading at the instruction provided with the scale before starting to answer. They were also requested not to omit any item in the scale and they were encouraged to answer all the items by telling that, there is no right or wrong answer to any item. All possible clarifications were made to the problems if faced by the respondents. There was no time limit for the respondents to answer all the items of the scale. After completing of their tasks, the answered questionnaires were collected from them. Finally, they were given thanks for their sincere cooperation.

\section{RESULTS}

In order to analyze the data independent sample $t$-test, zero order Pearson correlation, and simple regression analysis were applied on the obtained scores. According to objectives the results of the study have been presented in three parts.

In the first part, according to gender mean and standard deviations of suicidal ideation and life satisfaction was determined (Table 1).

Then, in the second part, mean and standard deviation of suicidal ideation were calculated based on having bitter experiences in romantic relationship.

Finally, in the third part of the result section, the role of life satisfaction on suicidal ideation was measured (Table 3 \& 4).

Table 1 Mean Differences of Suicidal Ideation and Life Satisfaction by Gender

\begin{tabular}{|l|l|l|l|l|}
\hline Variables & Gender & $\mathbf{N}$ & $\mathbf{M}$ & SD \\
\hline Suicidal ideation & Male & 60 & .67 & 1.39 \\
\cline { 2 - 5 } & Female & 60 & 2.50 & 7.39 \\
\hline \multirow{2}{*}{ Life satisfaction } & Male & 60 & 22.23 & 5.38 \\
\cline { 2 - 5 } & Female & 60 & 23.48 & 6.80 \\
\hline
\end{tabular}

As shown in Table1, the level of suicidal ideation differed between male and female students. The suicidal ideation score for female students was much higher than those of male students. And the difference of their mean score was 1.83. The result from $t$-test indicated that there was 


\section{Can Life Satisfaction Independently Predict Suicidal Ideation of Male And Female?}

no significant difference between male and female students in suicidal ideation $(t=-1.88, p>$ .05). On the other hand, life satisfaction of male and female students was almost similar and the result of $t$-test failed to reach at statistical significant value $(t=-1.11, p>.05)$.

Table 2 Mean Differences of Suicidal Ideation by Having Bitter Experiences in Romantic Relationship

\begin{tabular}{|l|l|l|l|l|}
\hline Variable & $\begin{array}{l}\text { Having bitter } \\
\text { Experiences }\end{array}$ & $\mathbf{N}$ & $\mathbf{M}$ & SD \\
\hline Suicidal ideation & Yes & 41 & 3.41 & 8.47 \\
\cline { 2 - 5 } & No & 79 & .63 & 2.14 \\
\hline
\end{tabular}

Table 2 concluded that the participants who had bitter experiences in romantic relationship scored much higher on suicidal ideation than did others who had not better experiences in romantic relationship. The result also revealed that there is a significant difference between these two groups (who had bitter experiences and who did not have bitter experiences in romantic relationship) in suicidal ideation $(t=2.76, p<.01)$.

Table 3, Zero-Order Correlation between Suicidal Ideation and Life Satisfaction

\begin{tabular}{|l|l|}
\hline Suicidal ideation & Life satisfaction \\
\cline { 2 - 2 } & $-.316^{* *}$ \\
\hline
\end{tabular}

${ }^{*} p<.01$

Zero-order correlations (Table 3) showed that suicide ideation was significantly negatively correlated with life satisfaction $(r=-.316 ; p<.01)$.

Table 4, Summary of Simple Regression Analysis of Suicidal Ideation by Life Satisfaction According to Gender

\begin{tabular}{|l|l|l|l|l|}
\hline Variable & Gender & $\boldsymbol{B}$ & $\boldsymbol{t}$ & $\boldsymbol{p}$ \\
\hline \multirow{2}{*}{ Life satisfaction } & Male $(n=60)$ & -.166 & -1.28 & .205 \\
\cline { 2 - 5 } & Female $(n=60)$ & -.466 & -4.01 & .000 \\
\hline
\end{tabular}

Note. $\mathrm{R}^{2}=.02$ (Adjusted $\mathrm{R}^{2}=.01$ ), $F(1,58)=1.64, p>.05$ for male; $\mathrm{R}^{2}=.21$ (Adjusted $\mathrm{R}^{2}=$ $.20), F(1,58)=16.11, p<.001$ for female.

To determine the significant effect of life satisfaction on suicidal ideation for both male and female students a simple regression analysis was conducted. In case of male students, life satisfaction was not a significant predictor of suicidal ideation (see Table 4). Life satisfaction explained only $2 \%$ of the variance in suicidal ideation for male participants. However, life satisfaction explained $21 \%$ of the variance in suicidal ideation for female students. And the regression equation predicting suicidal ideation for females revealed that life satisfaction was significantly a strong predictor (Table 4). 


\section{DISCUSSION}

The present study was designed to study the role of life satisfaction on suicidal ideation for both male and female students. In order to measure the variables of this study two questionnaires as well as personal information form were applied on one hundred and twenty undergraduate students purposively selected from University of Chittagong in Bangladesh.

Five hypotheses were formulated to test in the present study. The first hypothesis stated that female students will score significantly higher on suicidal ideation than do male students. The result showed that female students were found to be slightly greater risk than male students for suicidal ideation. The mean score of suicidal ideation was 2.50 for female students and .67 for male students. But the difference of scores was not significant $(t=-1.88, p>.05)$. It means that there is no significant difference between male and female students on suicidal ideation. The result is consistent with prior research (Spirito, Sterling, Donaldson, \& Arrigan, 1996; Galaif, Chou, Sussman, \& Dent, 1998).

The level of life satisfaction for female students was slightly higher than that for male students (see table 1). This result is completely opposite to second hypothesis. Hypothesis-2, female students will score significantly lower on life satisfaction as compared to male students, was taken because women have traditionally possessed less power and fewer resources than men. For example, in Bangladeshi culture men possess more status and freedom. However, there might have other explanations regarding this result. Female students have fewer opportunities to study in a university as compared to male students they are because not encouraged for higher education as much as males are encouraged by their patents. Besides, because of early marriage most of them finish their student life at secondary education level. So, studying in a university is one of the great sources for increasing life satisfaction, especially for women in Bangladesh. Besides, according to Chee, Pino, \& Smith, (2005) some other possible explanations for the difference in life satisfaction by gender could be the value systems of female students. They are more positive in their ratings than male students. Female students tend to feel more supported both academically and personally by faculty, than male students do, which seems to be a great contributory factor for their overall feeling of satisfaction (Sax, \& Harper, 2005).

The results revealed that the students who had bitter experiences in romantic relationship were found to be more prone to suicidal tendencies than who had not. The suicidal ideation scores were 3.41 for students who experienced bitter consequences in their romantic relationship and 0.63 for students who did not experienced such consequences. And the difference is significant ( $t$ $=2.76, p<.01)$. This result is consistent with previous research findings. Fisher, Brown, Aron, Strong, \& Mashek, (2010) found that an acute sense of loss and clinical level of depressive mood might occur because of rejection in romantic relationship and in extreme cases suicidal or homicidal behaviors might also happen. According to Batterham, et al., (2014) a rejection in relationship can result in a significant increase in suicidal thoughts, plan and attempts. 


\section{Can Life Satisfaction Independently Predict Suicidal Ideation of Male And Female?}

An investigation of the relationship between life satisfaction and suicidal ideation revealed that life satisfaction is negatively correlated with suicidal ideation $(r=-.316 ; p<.01)$. This finding indicates that the higher the life satisfaction the lower the suicidal ideation. This result is in harmony with the presumed hypothesis and the previous evidences (Johal \& Sharma, 2016).

An advanced exploration revealed that in case of female students life satisfaction is a significant predictor of suicidal ideation. In a simple regression analysis, it was found that life satisfaction can predict $21 \%$ variation of suicidal ideation of female respondents. And this prediction was found to be significant with an alpha level of $.000\left(R^{2}=.21 ; p<.001\right)$. Standardized beta coefficient $(\beta)$ of the regression analysis of life satisfaction determined that 1 unit change of life satisfaction reduced .466 unit of suicidal ideation $(\beta=-.466 ; p<.001)$. Whereas a regression equation demonstrated that life satisfaction is not a significant predictor of suicidal ideation for male students $\left(R^{2}=.02 ; p>.05\right)$. And life satisfaction can predict only $2 \%$ variation of suicidal ideation of male participants. Life satisfaction is more changeable than personality and is more influenced by environmental factors which appear to extensively influence well-being (Fujita, \& Diener, 2005). Therefore, to reduce suicidal ideation of female students, it is mandatory to improve life satisfaction by intervention programs.

There may have other crucial factors (e.g., coping skills) can explain relation between students' life satisfaction and suicidal behaviors. According to Huebner, \& Alderman, (1993), and Huebner, Drane, \& Valois, (2000) life satisfaction is associated with coping skills, fulfilled goals, needs and wishes of youth. Students' difficulties in coping with stress and challenges might mediate the association between life satisfaction and suicide. Usually, many students are not skilled in five dimension of their life such as goal setting, problem solving, decision making, stress management, and communication (Valois, Vincent, McKeown, Garrison, \& Kirby, 1993). As a result of these poor coping skills dissatisfied students might involve in suicidal ideation or suicide behaviors. Lack of these life skills can result in the inability to manage and cope with various stressors, lead to irrational cognitive judgements, suicide attempts and the consecutive consequences (Garrison, McKeown, Valois, \& Vincent, 1993). Therefore, future research should include measures of adolescent coping skills to examine the complex interrelationships among life satisfaction, coping behavior, and suicidal thoughts and behaviors among students.

There are considerable limitations of the present study. First of all, the study was conducted in a comparatively small sample selected from a single public university of Bangladesh. So, it requires replications among a large sample and in a disparate population. Then, the generalizability of the findings from the present study is questionable because the participants were chosen by purposive non random sampling techniques. For this reason to escalate generalizability a random selection is needed. Finally, a cross - sectional research design was used in the present study which makes it difficult to establish a causal relationship between life satisfaction and suicidal ideation. And this is why a longitudinal research design is needed for indicating the definite role of life satisfaction in influencing the development suicidal ideation. 
REFERENCES

Adcock, A. G., Nagy, S., \& Simpson, J. A. (1991).Selected risk factors in adolescent suicide attempts. Adolescence 26, 817-28.

Alexopoulos, G. S., Bruce, M. L., Hull, J., Sirey, J. A., \& Kakuma, T. (1999). Clinical Determinants of Suicidal Ideation and Behavior in Geriatric Depression. Archives of General Psychiatry, 56(11), 1048-1053.doi: 10.1001/archpsyc.56.11.1048

Batterham, P.J., Fairweather-Schmidt, A.K., Butterworth, P., Calear, A.L., Mackinnon, A.J., \& Christensen, H., (2014). Temporal effects of separation on suicidal thoughts and behaviours. Soc. Sci. Med. 111, 58-63.

Beck , A. T., Kovacs, M., Weissman, A. (1979). Assessment of suicidal ideation: The Scale for Suicide Ideation. J Consult Clin Psychol, 47(2), 343-352.

Beck, A. T., Brown, G. K., Steer, R. A., Dahlsgaard, K. K., \& Grisham, J. R. (1999). Suicidal ideation at its worst point: A predictor of eventual suicide in psychiatric outpatients. Suicide Life Threat Behav, 29(1), 1-9.

Beck, A. T., Steer, R. A., Kovacs, M., and Garrison, B. (1985). Hopelessness and eventual suicide: A 10- year prospective study of patients hospitalized with suicidal ideation. American Journal of Psychiatry, 142(5), 559-563.

Chee, K. H., Pino, N. W., \& Smith, W. L. (2005). Gender Differences in the Academic Ethic and Academic Achievement. College Student Journal, 39(3), 604-618.

Chen, P., Lee, L., Wong, K., \& Kaur, J. (2005). Factors relating to adolescent suicidal behavior: a cross-sectional Malaysian school survey. Journal of Adolescent Health, 37(4), 337.e11337.

Diener, E. (1994). Assessing subjective well-being: Porgress and opportunities. Social Indicator Research, 31, 103-157.

Diener, E., Emmons, R. A., Larsen, R. J., \& Griffin, S. (1985). The satisfaction with life scale. Journal of Personality Assessment, 49, 71-75.

Diener, E., Sapyta, J. J., \& Suh, E. (1998). Subjective well-being is essential to well-being. Psychological Inquiry, 9(1), 33-37.

Diener, E., Suh, E., \& Oishi, S. (1997). Recent findings on subjective well-being. Indian Journal of Clinical Psychology, 24, 25-41.

Fisher, H. E., Brown, L. L., Aron, A., Strong, G., \& Mashek, D. (2010). Reward, addiction, and emotional regulation systems associated with rejection in love. Journal of Neurophysiology, 104, 51-60.

Frisch, M. B. (1998). Quality of life therapy and assessment in health care. Clinical Psychology: Science and Practice, 5, 19-40.

Fujita, F., \& Diener, E. (2005). Life satisfaction set point: Stability and change. J Pers Soc Psychol, 88(1), 158-164.

Galaif, E. R., Chou, C. P., Sussman, S., \& Dent, C. W. (1998). Depression, suicidal ideation, and substance use among continuation high school students. Journal of Youth and Adolescence, 27, 275-299.

Garrison, C. Z., Jackson K. I., Addy, C. L., McKeowan, R. E., \& Waller, J. (1991). Suicidal behaviors in young adolescents. Am J Epidemiol, 133, 1005-1014.

Garrison, C.Z., McKeown, R., Valois, R. F., \& Vincent, M. L. (1993). Aggression, substance use, and suicidal behaviors in high school students. AmericanJournal of Public Health, 83(2), pp. 179-184.

Gilman, R., \& Huebner, E. R. (1997). Children's reports of their life satisfaction: Convergence across raters, time and response formats. School Psychology International, 18, 133-147. 


\section{Can Life Satisfaction Independently Predict Suicidal Ideation of Male And Female?}

Goldstein, R.B., Black, D.W., Nasrallah, A., \& Winokur, G. (1991).The prediction of suicide: Sensitivity, specificity, and predictive value of a multivariate model applied to suicide among 1906 patients with affective disorders. Archives of General Psychiatry, 48,418422.

Haight, B. K., \& Hendrix, S. A. (1998). Suicidal intent/life satisfaction: Comparing the life stories of older women. Suicide and LifeThreatening Behavior, 28(3), 272-284.

Harlow, L., Michael, D., Newcomb, \& Bentler, M. (1985). Depression, self-derogation, substance use, and suicide ideation: Lack of purpose in life as a mediational factor. Journal of Clinical Psychology, 42, 5-21. DOI: 10.1002/1097-4679(198601)42:13.0.CO; 2-9

Heisel, M. J., \& Flett, G. L. (2004). Purpose in life, satisfaction with life, and suicide ideation in a clinical sample. Journal of Psychopathology and Behavioral Assessment, 26(2), 127135. doi: 10.1023/B:JOBA.0000013660.22413.e0

Heisel, M. J., \& Flett, G. L. (in press).Meaning in life and the prevention of elderly suicidality. In P. T. P. Wong, M. McDonald, \& D. Klaassen (Eds.), Advances in the positive psychology of meaningand spirituality: Selected proceedings from the first internationalconference on personal meaning. Abbotsford, BC: INPM Press.

Heisel, M. J., \& Fus'e, T. (1999). College student suicide ideation in Canada and in Japan. Psychologia: An International Journal of Psychology in the Orient, 42(3), 129-138.

Huebner, E.S., \& Alderman, G. L. (1993). Convergent and discriminant validation of a children's life satisfaction scale: Its relationship to self- and teacher reported psychological problems and school functioning. Social Indicators Research, 30, pp. 71-82.

Huebner, E.S., B.A. Funk, B. A., \& Gilman, R. (2000). Crosssectional and longitudinal psychosocial correlates of adolescent life satisfaction reports. Canadian Journal of School Psychology 16, 53-64.

Huebner, E.S., Drane, J. W., \& R.F. Valois, R. F. (2000). Levels and demographic correlates of adolescent life satisfaction reports. School Psychology International 21(3), pp. 281-292.

Hutchinson, G., Simson, D. T., Bain, B. C., Wyatte, G. E., Tucker, M. B., \& Lefranc, E. (2004). Social and health determinants of well being and life satisfaction in Jamaica. The International Journal of Social Psychiatry, 50, 43-53.

Ilyas, Q. S. M. (2001). Bangla version of Satisfaction with Life Scale. Unpublished Manuscript, Department of Psychology, University of Dhaka.

Jamshiedzadeh, F.L., Rafiei, H., Yasami, M. T., Rahimi, A. S., \& Azam,K. (2001). Suicide trend and suicidal attempts in Eilam province (IRAN) during 1994-2001. Social Well Fair Scientific Res. Q., 3, 329-349.

Johal, D. S. \& Sharma, M. (2016). Suicidal ideation and life satisfaction among adolescents: A correlational study. IOSR Journal Of Humanities And Social Science (IOSR-JHSS), 21, 23-28.

Kachur, S. L. Potter, K. Powell \& Rosenberg, M. (1995). Suicide: Epidemiology, prevention, treatment. Adolesc. Med., 6, 171-182.

Koivumaa-Honkanen, H., Honkanen, R., Viinam“aki, H., Heikkil“a, K., Kaprio, J., \& Koshenvuo, M. (2001). Life satisfaction and suicide: A 20-year follow-up study. American Journal of Psychiatry, 158(3), 433-439.

Lagaraj, M., Felix, J. W., \& Vedapriya, D. R. (2005). Attempted suicide in adolescents reported at a medical college hospital in Tamilnadu-some observations. Indian J Prev Soc Med, 36, 68-72. 


\section{Can Life Satisfaction Independently Predict Suicidal Ideation of Male And Female?}

Laghi, F., Baiocco, R., D'Alessio, M., \& Gurrieri, G. (2009). Suicidal ideation and time perspective in high school students. European Psychiatry, 24, 41-46.

Lazarus, R. S. (1991). Emotion and adaptation. New York: Oxford University Press.

Lee, S., Tsang, A., Li, X. Y., Phillips, M. R., \& Kleinman, A. (2007). Attituds toward suicide among Chinese people in Hong Kong. Suicide Life Threats Behave, 37, 565-575.

Lester, D. (1998). Life Satisfaction, Suicide, and Homicide. Perceptual and Motor Skills, 87, 126.

Lewinsohn, P. M., Hops, H., Roberts, R. E., Seeley, J. R., \& Andrews, J. A. (1993). Adolescent psychopathology: Prevalence and incidence of depression and other DSM-III-R disorders in high school students. Journal of Abnormal Psychology, 102, 133-144.

Lewinsohn, P. M., Rohde, P., \& Seeley, J. R. (1994). Psychosocial risk factors for future adolescent suicide attempts. Journal of Consulting and Clinical Psychology, 62(2), 297305. doi: 10.1037/0022-006X.62.2.297

Mackenzie, S., Wiegel, J. R., Mundt, M., Brown, D., Saewyc, E., Heiligenstein, E., Harahan, B., \& Fleming, M. (2011). Depression and suicide ideation among students accessing campus health care. , 81(1), 101-7. doi: 10.1111/j.1939-0025.2010.01077.x

McAuliffe, C., Carcoran, P., Keeley,H. S., \& Perry, I. J. (2003). Risk of suicide ideation associated with problem-solving ability and attitudes toward suicidal behavior in university students. Crisis, 24(4), 160-7.

Neg, K. M., Loy, J., Gudmunson, C. G. \& Cheong, W. N. (2009). Gender Differences in Marital and Life Satisfaction among Chinese Malaysians. Sex Roles, 60, 33- 43.

Olfson, M., Weissman, M. M., Leon, A. C., Sheehan, D. V. \& Farbre, L. (1996). Suicidal ideation in primary care. $J$ Gen Intern Med, 11, 447-453.

Ozer, M. A. (2000). Study on the life satisfaction of elderly individuals living in family environment and nursing homes. Turkish Journal of Geriatrics, 7, 33-36.

Park, H. S., Koo, H. Y., \& Schepp, G. (2005). Predictors of suicide ideation for adolescents by gender. Taehan Kanho Hakhoe Chi, 35, 1433-1442.

Pavot,W.,\& Diener, E. (1993). Review of the satisfaction with life scale. Psychological Assessment, 5(2), 164-172.

Reinherz, H. Z., Giaconia, R. M., Silverman, A. B., Friedman, A., Pakiz, B., \& Frost, A. K. (1995). Journal of the American Academy of Child and Adolescent Psychiatry, 34(5), 599-611. doi: 10.1097/00004583-199505000-00012

Rich, A. R., Kirkpatrick-Smith, J., Bonner, R. L., and Jans, F. (1992). Gender differences in the psychosocial correlates of suicidal ideation among adolescents. Suicide Life-Threat. Behav. 22, 364-373.

Rihmer, Z (2007). Suicide risk in mood disorders. Current Opinion In Psychiatry, 20(1), 17-22.

Ruangkanchanasetr, S., Plitponkarnpim, A., Hetrakul, P., \& Kongsakon, R. (2005). Youth risk behavior survey: Bangkok, Thailand. Journal of Adolescent Health, 36, 227-235.

Sandin, B., Chorot, P., Santed, M. A., Valiente, R. M., \& Joiner, T. E. Jr. (1998). Negative life events and adolescent suicidal behavior: a critical analysis from the stress process perspective. J Adolescent, 21(4), 415-26.

Sax, L. J., \& Harper, C. E. (2005). Origins of the Gender Gap: Pre-College and College Influences on Differences Between Men and Women. Paper presented at the Annual Meeting of the Association for Institutional Research, San Diego.

Schweitzer, R., Klayich, M., \& McLean, J. (1995). Suicidal ideation and behaviours among university students in Australia. Aust N Z J Psychiatry, 29(3), 473-9. 
Sherer, M. (1985). Depression and suicidal ideation in college students. Psychological Reports, Volume 57, pp. 1061-1062.

Sidhartha, T., \& Jena, S. (2006). Suicidal behavior in adolescents. Indian J Pediatr, 73(9), 783788.

Spirito, A., Sterling, C. M., Donaldson, D. L., \& Arrigan, M. E. (1996). Factor analysis of the suicide intent scale with adolescent suicide attempters. J Pers Assess, 67(1), 90-101.

Stephenson,H.,Pena-Shaff, J., \& Quirk, P. (2006). Predictors of college student suicidal ideation: Gender differences. College Student Journal, 40, 109-117.

Stewart, Mary, E., Donaghey, Claire, Deary, Ian, J., Ebmeier, \& Klaus, P. (2008). Suicidal thoughts in young people: Their frequency and relationships with personality factors. Personality and Individual Differences, Vol. 44, No. 4, p. 809-820.

The United News of Bangladesh (2012). Special report : suicide in Bangladesh. http://www.dispatchesinternational.org/?p=990

Tomory, M., Zalar, B., \& Plesnicar, B. K. (2000). Gender differences in psychosocisl risk factors among slovenian adolescents. Adolescence, 35 (139), 431-43.

Uddin, M. K., \& Hossain, S. (2007). Bangla version of Suicidal Ideation Questionnaire. Unpublished Manuscript, Department of Psychology, University of Dhaka.

Valois, R.F., Vincent, M. L., McKeown, R., Garrison, C., \& Kirby, S. (1993). Adolescent risk behaviors and the potential for violence: A look at what's coming to campus. American Journal of College Health, 41(4), pp. 141-147.

World Health Organization (WHO) (2014). World Health Rankings. Bangladesh : Suicide. http://www.worldlifeexpectancy.com/bangladesh-suicide

World Health Organization (WHO) (2016). Preventing suicide : a global imperative. http://www.who.int/mental_health/suicide-prevention/en/

Yao,Y. S., Chang, W. W., Jim, Y. L., Chen,Y., He, L. P., \& Zang, L. (2014). Life satisfaction, Coping, Self-Esteem and Suicidal ideation in Chinese Adolescents: A school -based study. Child: Care, Health and Development, 40, 747-752.

Zhang, J., \& Jin, S. (1996). Determinants of suicide ideation: A comparison of Chinese and American college students. Adolescence, 31, 451-467. 